\title{
ANALISIS PERAMALAN HARGA EMAS DI INDONESIA PADA MASA PANDEMI COVID-19 UNTUK INVESTASI
}

\author{
Dyah Makutaning Dewi ${ }^{1}$, Muhammad Zaky Nafi' ${ }^{2}$, Nasrudin ${ }^{3}$ \\ ${ }^{1,2}$ Badan Pusat Statistik, ${ }^{3}$ Politeknik Statistika STIS \\ ${ }^{1}$ dyahfriendly@gmail.com, ${ }^{2}$ zaky.nafi@bps.go.id, ${ }^{3}$ nasrudin@ stis.ac.id
}

Diterima: Desember 2020; Disetujui: Februari 2021

\begin{abstract}
Pandemic Coronavirus Disease-2019 (Covid-19) is an unusual occurrence. The Covid-19 makes people hesitant to invest. This is because the world economy is not in good condition. Gold investment is one of the safest investments during the Covid-19 pandemic. The precious metal is widely chosen because the majority of the public is familiar with gold and easy to reach. In addition, because the price of gold tends to be stable and rarely inhabits the price drop, it is actually currently experiencing an increase in the price in a short time. One way to know the picture of gold price in Indonesia so that people are interested in investing in precious metals is to do forecasting using ARIMA Box-Jenkins method. The purpose of this research is to obtain gold price predictions in Indonesia over the next 30 days. The results of the analysis showed that ARIMA model $(1,1,1)$ so that it can be concluded that the gold price prediction of the next 30 days continues to increase with the percentage of training data errors by 1,005 percent and the validation of the forecast from testing data by 3,93 percent.
\end{abstract}

Keyword: ARIMA, covid-19, Indonesia, investment, price gold.

Abstraksi. Pandemi Coronavirus Disease-2019 (Covid-19) merupakan kejadian yang tidak biasa. Adanya Covid-19 membuat masyarakat ragu dalam melakukan investasi. Hal ini dikarenakan kondisi perekonomian dunia tidak sedang dalam kondisi baik. Investasi emas merupakan salah satu investasi yang cukup aman di masa pandemi Covid-19. Logam mulia tersebut banyak dipilih karena mayoritas masyarakat telah familiar terhadap emas serta mudah dijangkau. Selain itu, dikarenakan harga emas cenderung stabil dan jarang mengalami penurunan harga, justru saat ini mengalami peningkatan harga dalam waktu yang singkat. Salah satu cara untuk mengetahui gambaran harga emas di Indonesia agar masyarakat tertarik melakukan investasi logam mulia tersebut adalah melakukan peramalan dengan menggunakan metode ARIMA Box-Jenkins. Tujuan penelitian ini adalah memperoleh prediksi harga emas di Indonesia selama 30 hari ke depan. Hasil analisis menunjukkan bahwa didapatkan model ARIMA (1,1,1) sehingga dapat disimpulkan bahwa prediksi harga emas 30 hari ke depan terus mengalami peningkatan dengan persentase kesalahan training data sebesar 1,005 persen serta validasi ramalan dari testing data sebesar 3,93 persen.

Kata kunci: ARIMA, covid-19, harga emas, investasi, Indonesia

\section{PENDAHULUAN}

Pandemi Coronavirus Disease-2019 (Covid-19) merupakan kejadian yang tidak biasa. Tidak hanya berdampak pada kesehatan, pandemi tersebut telah berdampak di dalam berbagai aspek kehidupan. Sejak terjadi wabah Covid-19 di Wuhan, Cina pada tahun 2019 membuat masyarakat mengurangi aktivitas di luar rumah. Tidak berlangsung lama, wabah Covid-19 pun menyebar di berbagai belahan dunia, salah satunya Indonesia.

Pada 2 Maret 2020, secara resmi Presiden Republik Indonesia mengumumkan bahwa Indonesia mengalami kasus pertama Covid-19. 
Namun hingga saat ini wabah Covid-19 masih terjadi di negeri ini.

Gambar 1 menunjukkan bahwa kasus terkonfirmasi Covid-19 terus mengalami peningkatan selama periode 1 Agustus 2020 hingga 17 Agustus 2020 di Indonesia. Hal tersebut diiringi dengan peningkatan jumlah pasien yang sembuh, meninggal, maupun sedang dalam perawatan atau isolasi mandiri.
Berdasarkan data Satuan Tugas Penanganan Covid-19, pada 17 Agustus 2020 jumlah terpapar Covid-19 di Indonesia yang tersebar di 34 provinsi yang terdiri dari 483 kabupaten atau kota, jumlah terkonfirmasi masyarakat yang positif terhadap Covid-19 sebanyak 141.370 jiwa, jumlah pasien yang sembuh sebanyak 94.458 jiwa sedangkan jumlah pasien yang meninggal dunia sebanyak 6.207 jiwa.

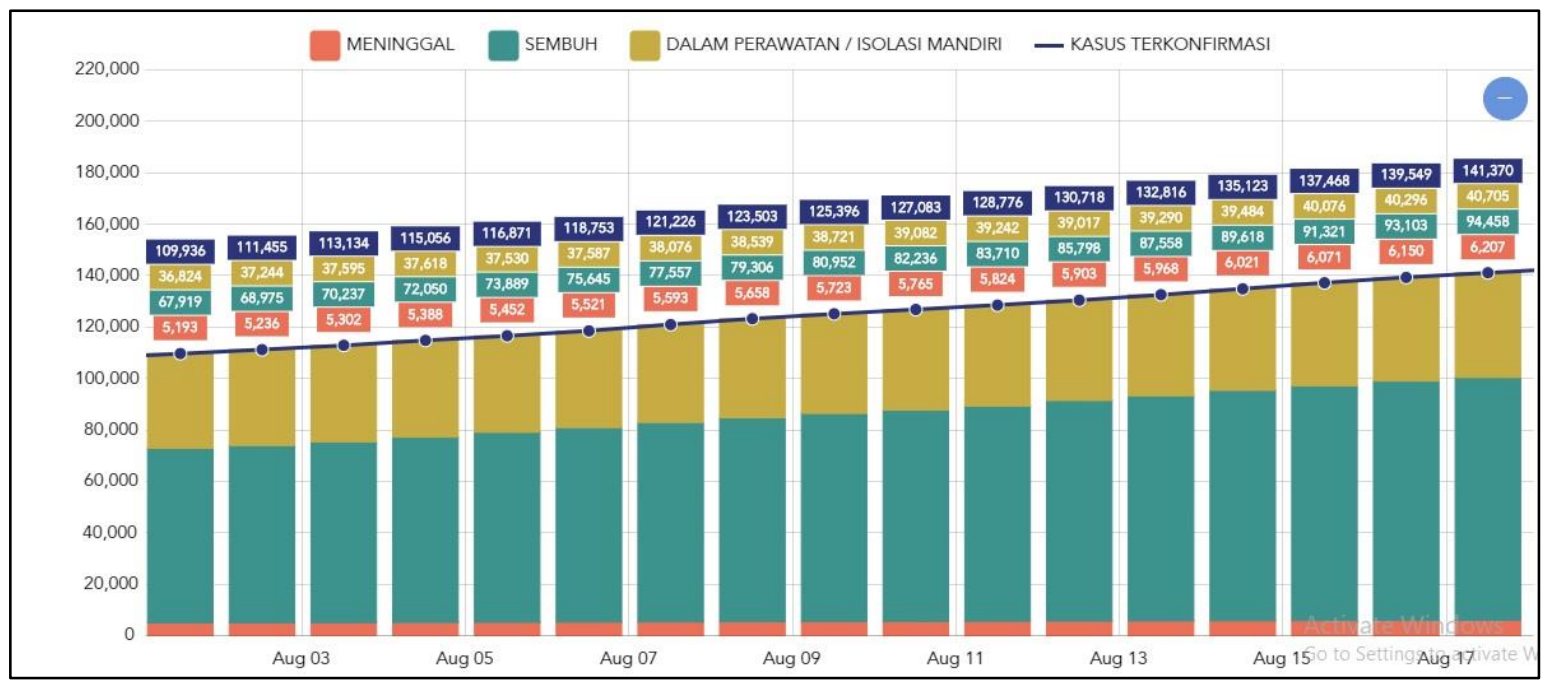

Gambar 1. Peta Sebaran Covid-19 di Indonesia Periode 1 Agustus-17 Agustus 2020 Sumber: covid19.go.id/peta-sebaran, 2020

Kepala daerah di berbagai wilayah Indonesia menanggapi kejadian tersebut dengan berbagai cara agar penularan Covid19 tidak mudah cepat menular ke masyarakat. Akibatnya, aktivitas seperti bersekolah dan bekerja terkadang harus dilakukan di rumah. Berdasarkan Publikasi Badan Pusat Statistik (BPS) Tinjauan Big Data terhadap Dampak Covid-19 menunjukkan bahwa adanya peningkatan sebesar 9,5 persen setiap harinya aktivitas masyarakat di tempat tinggal akibat diberlakukannya Work From Home (WFH) dan terjadi penurunan aktivitas rata-rata sebesar 16,5 persen per harinya di tempat kerja. Kemudian, apabila dirinci lebih lanjut yaitu adanya kebijakan WFH pada Maret
2020 dan Pembatasan Sosial Berskala Besar (PSBB) pada April 2020, kebijakan yang dibuat oleh Pemerintah Provinsi DKI Jakarta tersebut mampu menekan mobilitas masyarakat. Namun, kebijakan WFH dan PSBB belum mampu mengatasi secara tuntas dalam memutus rantai penyebaran Covid-19.

Telah berbulan-bulan Indonesia dilanda Covid-19 dan berdampak di dalam berbagai aspek kehidupan, salah satunya aspek ekonomi dan berdampak pada investasi. Berdasarkan data BPS, kondisi ekonomi di Indonesia pada triwulan II tahun 2020 terhadap triwulan I tahun 2020 mengalami kontraksi pertumbuhan sebesar 4,19 persen. Adapun kondisi ekonomi di Indonesia pada 
kuartal II tahun 2020 terhadap triwulan II tahun 2019 mengalami kontraksi pertumbuhan sebesar 5,32 persen. Akibat adanya pembatasan di masa pandemi, beberapa perusahaan mengalami penurunan pendapatan sehingga mengganggu kondisi perekonomian masyarakat.

Dampak Covid-19 juga dirasakan oleh perekonomian negara lain. Misalnya harga pertanian turun sebesar 20 persen. Hal ini dikarenakan banyak negara yang memberlakukan social distancing dan menghindari perjalanan yang tidak diperlukan sehingga berdampak terhadap komoditas pertanian yang mudah basi. Selain itu, survei yang dilakukan British Plastics Federation (BPF) menunjukkan bahwa Covid-19 berdampak terhadap bisnis manufaktur di United Kingdom (UK). Adanya kebijakan isolasi mandiri sehingga kekurangan tenaga kerja sehingga bisnis manufaktur menjadi terganggu. Selain itu, bekerja dari rumah bukanlah pilihan yang layak dalam menjalankan bisnis manufaktur. Sebanyak lebih dari 80 persen responden mengantisipasi penurunan selama 2 kuartal berikutnya (Nicola, et.al, 2020). Selain itu, harga minyak West Texas Intermediate mengalami penurunan pada April tahun 2020 (Gharib, et. al, 2020).

Adanya Covid-19 membuat masyarakat ragu dalam melakukan investasi. Hal ini dikarenakan kondisi perekonomian dunia tidak sedang dalam kondisi baik. Salah satu investasi yang membuat masyarakat ragu dalam berinvestasi yaitu investasi saham. Indeks Harga Saham Gabungan (IHSG) terjatuh di level 5.361 ketika kejadian pertama Covid-19 diumumkan. Pada Bulan Maret, IHSG mengalami level sangat rendah yakni di level 3.937 pada 24 Maret 2020 sedangkan pada 27 Mei 2020, IHSG berada di posisi 4.626 (biz.kompas.com, 2020). Terjadinya level IHSG yang bergejolak, membuat masyarakat berhatihati dalam melakukan investasi di masa pandemi Covid-19.

Investasi emas merupakan salah satu investasi yang cukup aman di masa pandemi Covid-19. Logam mulia tersebut banyak dipilih karena mayoritas masyarakat telah familiar terhadap emas serta mudah dijangkau. Selain itu, dikarenakan harga emas cenderung stabil dan jarang mengalami penurunan harga, justru saat ini mengalami peningkatan harga dalam waktu yang singkat. Investasi emas pun lebih mudah untuk dicairkan sehingga dapat memenuhi kebutuhan yang mendesak (properti.kompas.com, 2020).

Pada 22 Juni 2020 harga emas mencapai Rp 803.596,00 per gram. Kemudian, pada 27 Juli 2020 harga emas mencapai Rp 904.185,00 per gram sedangkan pada 7 Agustus 2020 harga emas mencapai Rp 830.904,00 per gram (gold.org). Apabila dilihat dari harga beli dan harga jual kepingan emas, berdasarkan data tokopedia, pada 17 Agustus 2020 harga beli kepingan emas 1 gram, 5 gram, 10 gram, 50 gram, dan 100 gram secara berturut-turut sebesar Rp 982.000,00 per gram, Rp 4.910.000,00 per gram, Rp 9.820.000,00 per gram, Rp 49.100.000,00 per gram, dan Rp 98.200.000,00 per gram. Lain halnya dengan harga jualnya yaitu secara berturutturut sebesar Rp 937.720,00 per gram, Rp 4.688.600,00 per gram, Rp 9.377.200,00 per gram, Rp 46.886.000,00 per gram, dan Rp 93.772.000,00 per gram.

Apabila dikaitkan dengan Gambar 1, pada 1 Agustus hingga 17 Agustus 2020, harga emas di Indonesia cenderung mengalami peningkatan. Oleh karena itu, dapat dikaitkan bahwa kasus terkonfirmasi Covid-19 dapat memengaruhi sentimen masyarakat sehingga berdampak terhadap harga emas . Pada awal Agustus 2020 harga 
emas telah mencapai kisaran harga $\mathrm{Rp}$ 900.000,00 per gram.

Salah satu cara untuk mengetahui gambaran harga emas di Indonesia agar masyarakat tertarik melakukan investasi logam mulia tersebut adalah melakukan peramalan dengan menggunakan metode ARIMA Box-Jenkins. Penelitian meramalkan harga emas telah banyak dilakukan, misalnya meramalkan harga emas terhadap mata uang dolar Amerika Serikat (Mentacem \& Kurniawati, 2016), peramalan harga emas PT. Antam TBK Indonesia (Andriyanto, 2017; KURNIA et al., 2014), peramalan harga emas global (Christian \& Halim, 2016; Kusumadewi, 2014).

\section{METODE PENELITIAN Metode Pengumpulan Data}

Penelitian ini menggunakan data sekunder yang bersumber dari website gold.org berdasarkan acuan London Bullion Market Association selama periode 1 Januari 2020 hingga 14 Agustus 2020 kecuali hari libur dan tanggal-tanggal tertentu yang tidak tersedia di website. Data yang digunakan di dalam penelitian ini adalah harga emas. Harga emas yang digunakan adalah harga penutupan (closing price) harian dari harga emas per gram dengan satuan rupiah. Menurut Kamus Besar Bahasa Indonesia (KBBI), emas merupakan logam mulia yang berwarna kuning serta dapat ditempa dan dapat dibentuk (lambangnya Au, nomor atomnya 79, bobot atomnya 196,9665). Menurut Santoso (2013) sejak pertama kali ditemukan, emas telah menarik minat manusia karena keindahannya dan sifat mulianya. Seiring perkembangan zaman, emas menjadi lambang dari keindahan, kemegahan, kemakmuran, serta bernilai ekonomis tinggi.

\section{Metode Analisis}

Metode analisis yang digunakan di dalam penelitian ini meliputi analisis deskriptif dan analisis inferensia. Analisis deskriptif digunakan untuk mengetahui kondisi atau gambaran umum variabel yang digunakan di dalam penelitian. Analisis deskriptif yang digunakan di dalam penelitian ini berupa diagram batang yang menggambarkan rata-rata harga emas setiap bulannya serta grafik yang menggambarkan harga emas setiap harinya selama periode penelitian.

Analisis inferensia yang digunakan di dalam penelitian ini menggunakan ARIMA Box-Jenkins. Analisis peramalan adalah metode yang tepat dalam mengetahui kondisi harga emas di masa depan. Pada penelitian Salisu, et.al (2020) menggunakan analisis peramalan dan data time series sehingga menunjukkan hasil bahwa emas pada masa pandemi Covid-19 memiliki peran safe haven. Oleh karena itu, investor dapat memilih emas sebagai bentuk investasi untuk meminimalkan resiko.

ARIMA Box-Jenkins merupakan salah satu jenis metode yang melibatkan time series data. Salah satu keuntungan menggunakan metode ini adalah dapat membuat model meskipun hanya menggunakan satu variabel. Kemudian, metode ini dapat digunakan untuk analisis peramalan. Oleh karena itu, pada penelitian ini ARIMA Box-Jenkins digunakan untuk analisis peramalan harga emas selama periode 1 Januari 2020 hingga 14 Agustus 2020 kecuali hari libur dan tanggal-tanggal tertentu yang tidak tersedia. Model yang digunakan di dalam penelitian ini adalah sebagai berikut:

lngold $_{t}=\frac{\left(1-\beta_{j} B\right) e_{t}}{\left(1-\alpha_{i} B\right)(1-B)}$

Keterangan:

$\operatorname{lngold}_{t}$ : harga emas pada waktu ke-t

$\operatorname{lngold}_{t-i}$ : harga emas pada waktu ke-t-i 
$\alpha_{i} \quad$ : koefisien AR

$\beta_{j} \quad$ : koefisien MA

$e_{t} \quad$ : nilai error white noise pada waktu ke-t

$e_{t-j}$ : nilai error white noise pada waktu ke-t-j

Adapun tahapan-tahapan dalam melakukan analisis menggunakan ARIMA Box-Jenkins adalah sebagai berikut:

1. Membagi data menjadi 2 yaitu training data dan testing data.

Training data digunakan untuk menentukan model ARIMA yang digunakan sedangkan testing data digunakan untuk validasi ramalan. Training data dalam penelitian ini merupakan data harga emas harian pada 1 Januari 2020 hingga 7 Agustus $2020(n=158)$ sedangkan testing data merupakan data harga emas harian pada 11, 13, 14 Agustus $2020(n=3)$.

\section{Melakukan uji stasioner}

Pengujian stasioner varians dan rata-rata pada data dilakukan untuk mengetahui kondisi kestasioneran data. Augmented Dickey Fuller (ADF) test digunakan untuk menguji stasioner pada rata-rata data. Apabila data belum stasioner pada varians maka dilakukan transformasi data. Kemudian, apabila data belum stasioner pada rata-rata maka dilakukan proses differencing hingga data tersebut stasioner.

3. Menentukan ordo $\mathrm{p}$ dan $\mathrm{q}$

Dalam menentukan ordo $\mathrm{p}$ dan $\mathrm{q}$ untuk parameter ARIMA yaitu dengan cara melihat pola autokorelasi (ACF) dan autokorelasi parsial (PACF).

4. Melakukan estimasi model

Dalam menentukan estimasi model ARIMA dapat menggunakan trial and error untuk mendapatkan model terbaik dengan melibatkan ordo p dan q.

5. Diagnosa model
Diagnosa model dilakukan untuk mengetahui apakah model tersebut baik untuk dilakukan peramalan. Jika residualnya white noise maka modelnya dapat dikatakan baik dan sebaliknya. Pengujian white noise dilakukan dengan menggunakan Ljung-Box test.

\section{Peramalan data}

Peramalan dilakukan untuk mengetahui harga emas per gram dalam 30 hari ke depan.

7. Menghitung persentase kesalahan training data dan validasi ramalan dari testing data

Dalam menghitung persentase kesalahan training data dan validasi ramalan dari testing data menggunakan ukuran Mean Absolute Percentage Error (MAPE). Rumus MAPE adalah sebagai berikut:

MAPE $=\frac{\sum_{i=1}^{n}\left|\frac{Y_{t}-\widehat{Y_{t}}}{Y_{t}}\right|}{n} \times 100$

\section{HASIL DAN PEMBAHASAN \\ Kondisi Harga Emas di Indonesia}

Akhir-akhir ini harga emas di berbagai negara mengalami peningkatan, salah satunya Indonesia. Hal ini dikarenakan terjadi pandemi Covid-19 yang menyerang dunia. Akibatnya, kondisi perekonomian terkena dampaknya. Pada 2 Maret 2020 Presiden Republik Indonesia menyampaikan kasus pertama terjadinya Covid-19 di Indonesia. Tak lama kemudian, pemerintah berupaya mengatasi agar penularan Covid-19 tidak mudah menyebar di kalangan masyarakat. Berbagai upaya yang dilakukan pemerintah seperti WFH dan PSBB membuat kondisi perekonomian terkena dampaknya sehingga harga emas pun cenderung mengalami peningkatan selama pandemi Covid-19. 


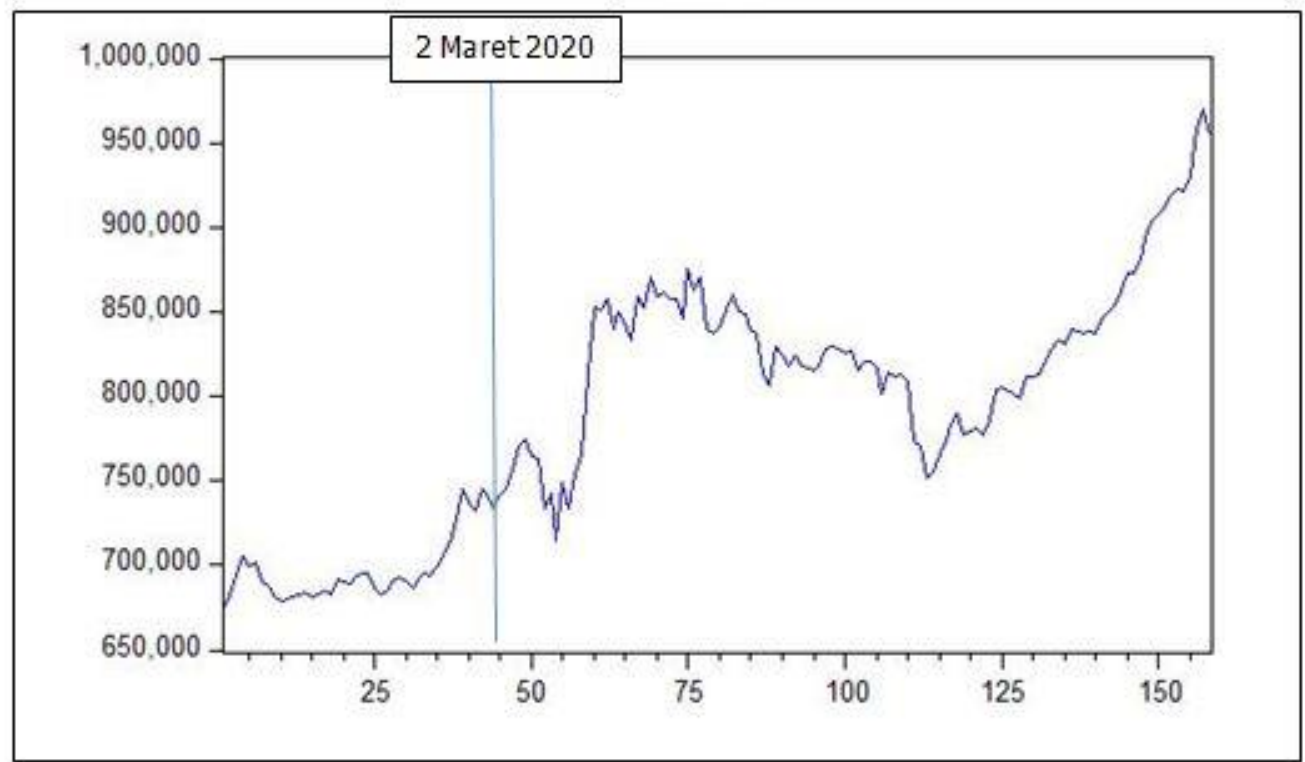

Gambar 2. Perkembangan Harga Emas di Indonesia 1 Januari hingga 14 Agustus 2020 Sumber: gold.org, diolah 2020

Gambar 2 menunjukkan selama periode 1 Januari 2020 hingga 14 Agustus 2020 harga emas di Indonesia mengalami fluktuatif. Semenjak adanya Covid-19 pada 2 Maret 2020, harga emas di Indonesia cenderung mengalami peningkatan. Namun sebenarnya setelah adanya Covid-19 di Wuhan, Cina pada akhir tahun 2019, harga emas di Indonesia mulai mengalami peningkatan secara bertahap. Pada 20 Februari 2020 harga emas di Indonesia sebesar Rp 713.583,00 per gram sedangkan pada 20 Januari 2020 sebesar Rp $683.882,00$ per gram. Tak lama kemudian, pada 23 Maret 2020 harga emas di Indonesia mencapai $\mathrm{Rp} 812.974,00$ per gram. Bahkan pada 27 Juli 2020 harga emas di Indonesia mencapai $\mathrm{Rp}$ 904.185,00.
Apabila dilihat secara rinci harga ratarata emas per gram setiap bulannya dapat dilihat pada Gambar 3. Gambar 3 menunjukkan rata-rata harga emas per gram tertinggi terjadi pada Bulan Agustus sebesar Rp 939.499,00 sedangkan rata-rata harga emas per gram terendah terjadi pada Bulan Januari sebesar Rp 687.679,00. Pada Bulan Juni harga emas mengalami penurunan sehingga rata-rata harga emas mencapai $\mathrm{Rp}$ 787.468,00. Harga emas mengalami penurunan dikarenakan beberapa negara telah mengurangi kebijakan pembatasan yang diberlakukan selama pandemi Covid19 sehingga memberikan optimisme jika perekonomian global akan membaik (money.kompas.com, 2020). Namun pada Bulan Juli dan Agustus harga emas mengalami peningkatan. 


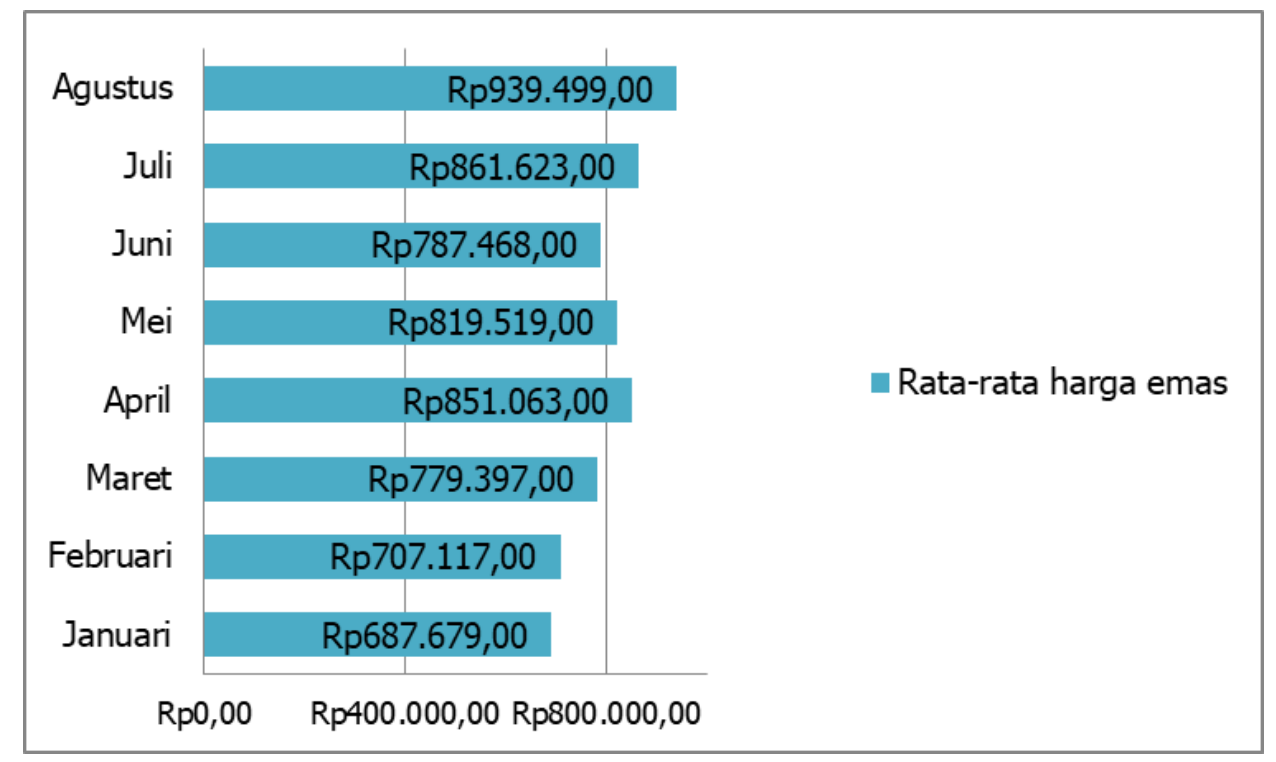

Gambar 3. Rata-Rata Harga Emas per Bulan di Indonesia Sumber: gold.org, diolah 2020

Harga emas mengalami peningkatan terutama ketika pandemi diakibatkan oleh kondisi perekonomian global yang sedang tidak dalam kondisi baik. Hal ini dikarenakan banyak negara yang mengalokasikan dana yang dimiliki untuk keperluan penanganan Covid-19. Selain itu, beberapa negara menerapkan kebijakan pembatasan bahkan kebijakan lockdown. Di tengah kondisi perekonomian global yang sedang tidak baik, para investor berusaha mencari perlindungan dalam berinvestasi. Akibatnya, permintaan terhadap emas cenderung meningkat selama pandemi Covid-19. Selain itu, adanya stimulus fiskal dan moneter besar-besaran yang ditempuh bank sentral global dan pemerintah sehingga membuat menarik dalam berinvestasi emas (cnbcindonesia.com).

\section{Analisis Model ARIMA}

Salah satu syarat utama dalam melakukan analisis ARIMA adalah data yang digunakan harus stasioner baik terhadap rata-rata maupun varians. Oleh karena itu, dilakukan pengujian terhadap kestasioneran data. Pada Gambar 4 menunjukkan bahwa data harga emas belum stasioner. Hal ini dikarenakan masih ditemukan trend dalam pola data tersebut yang menunjukkan harga emas mengalami peningkatan secara bertahap. Selain itu, dibuktikan pula dengan ADF test yang menunjukkan $p$-value $>0,05$ yaitu sebesar 0,8646 yang menunjukkan data tidak stasioner di level. 


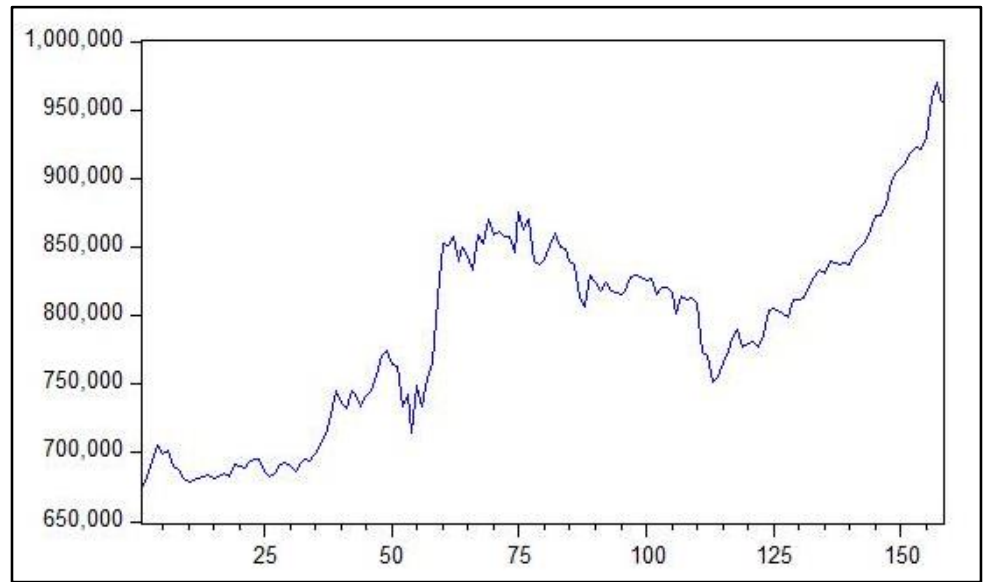

Gambar 4. Plot Time Series Data Harga Emas di Indonesia Sumber: gold.org, diolah 2020

Dalam mengatasi data yang tidak Hasil setelah dilakukan proses stasioner maka dilakukan beberapa langkah. transformasi data dan differencing 1 dapat Dalam mengatasi data tidak stasioner pada dilihat pada Gambar 5. Pada Gambar 5 varians maka dilakukan transformasi. Pada penelitian ini data diubah ke dalam bentuk logaritma natural. Kemudian, mengatasi data tidak stasioner pada rata-rata maka dilakukan proses differencing. Pada penelitian ini hanya membutuhkan proses differencing 1 . menunjukkan data telah stasioner baik pada varians maupun rata-rata. Hal ini dibuktikan pada proses differencing 1, hasil ADF test menunjukkan hasil $p$-value $<0,05$ yaitu sebesar 0,0000. Hal ini menunjukkan bahwa data harga emas telah stasioner pada differencing 1 .

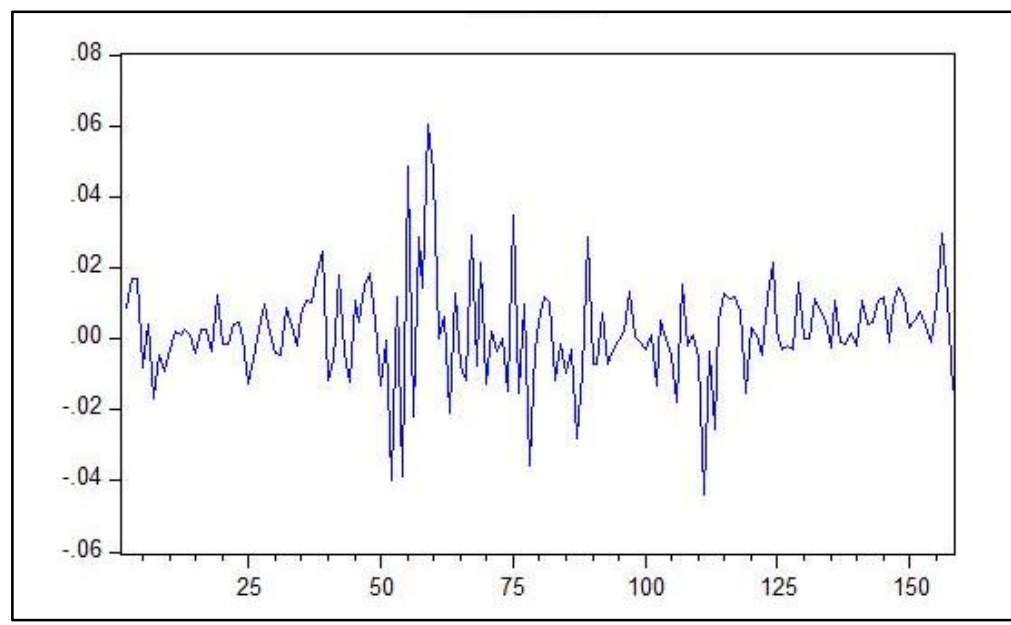

Gambar 5. Plot Time Series Data Harga Emas di Indonesia Setelah Diferencing 1 Sumber: gold.org, diolah 2020

Kemudian, dilakukan proses identifikasi model ARIMA dengan membangun model tentatif berdasarkan hasil kombinasi Autoregressive (AR) dan Moving Average (MA). Kombinasi ordo AR dan MA ditentukan dari pola ACF dan PACF.
Dalam penelitian ini diperoleh $\mathrm{AR}(1)$ dan MA(1) sehingga diperoleh dugaan model yaitu ARIMA $(0,1,0)$, ARIMA $(1,1,0)$, $\operatorname{ARIMA}(0,1,1), \quad$ dan ARIMA $(1,1,1)$ sebagaimana dapat dilihat pada Tabel 1. 
Tabel 1.

Model Tentatif ARIMA Box-Jenkins

\begin{tabular}{ccc}
\hline $\begin{array}{c}\text { Model } \\
\text { ARIMA }\end{array}$ & AIC & SBC \\
\hline$(0,1,0)$ & $-884,016$ & $-880,96$ \\
$(1,1,0)$ & $-882,237$ & $-876,125$ \\
$(0,1,1)$ & $-882,163$ & $-876,05$ \\
$(1,1,1)$ & $-885,187$ & $-876,019$ \\
\hline
\end{tabular}

Sumber: Analisis data

Berdasarkan Tabel 1 dapat diketahui tersebut memiliki parameter yang tidak bahwa nilai AIC dan SBC masing-masing signifikan sehingga dilakukan proses trial dari ARIMA $(0,1,1)$ sebesar -882,13 dan - and error. Pada proses trial and error 876,05. Kedua nilai tersebut memiliki nilai sehingga diperoleh model ARIMA terbaik AIC dan SBC terkecil di antara model yaitu ARIMA $(1,1,1)$. ARIMA lainnya. Namun, model ARIMA

Tabel 2.

Hasil Estimasi Parameter

\begin{tabular}{cccc}
\hline Parameter & Koefisien & $P$-value & Keterangan \\
\hline$\theta$ & 0,0022 & 0,0397 & Signifikan \\
$\alpha_{1}$ & $-0,6841$ & 0,0048 & Signifikan \\
$\beta_{1}$ & $-0,7945$ & $<, 0001$ & Signifikan \\
\hline
\end{tabular}

Sumber: Analisis data

Hasil estimasi parameter dari model berupa uji white noise residual dengan ARIMA $(1,1,1)$ dapat dilihat pada Tabel 2. pengujian independensi residual. Uji Pada Tabel 2 menunjukkan bahwa semua independensi residual pada penelitian ini parameter di dalam model tersebut menggunakan Ljung-Box test. Pada uji signifikan pada $\alpha=5$ persen. Kemudian, tersebut menunjukkan bahwa terjadi gagal dilakukan pengujian terhadap residual tolak $H_{0}$ pada sebagian besar lag dengan model ARIMA (1,1,1). Pengujian ini tingkat signifikansi 5 persen (Tabel 3).

Tabel 3.

Hasil uji independensi residual ARIMA Box-Jenkins.

\begin{tabular}{ccc}
\hline \multicolumn{3}{c}{ Uji Independensi Residual } \\
Lag & Chi-Square & P-value \\
\hline 12 & 15,73 & 0,1077 \\
18 & 16,12 & 0,4446 \\
24 & 24,14 & 0,2456 \\
30 & 29,73 & 0,3764 \\
\hline
\end{tabular}

Sumber: Analisis data 
Oleh karena itu, persamaan model ARIMA $(1,1,1)$ yang diperoleh adalah sebagai berikut:

$W_{t}=0,0022+0,3159 W_{t-1}+0,6841 W_{t-2}+$ $0,7945 e_{t-1}+e_{t}$

dengan $W_{t}=$ lngold

Berdasarkan Tabel 4 dapat dilihat hasil peramalan dengan model ARIMA $(1,1,1)$. Berdasarkan hasil ramalan tersebut menunjukkan bahwa harga emas di Indonesia per gram terus mengalami peningkatan selama 30 hari ke depan. Pada
16 hari ke depan yaitu sekitar akhir Agustus tahun 2020, harga emas telah mencapai Rp 1.001.237,00 per gram sedangkan 30 hari ke depan yaitu pada pertengahan September tahun 2020 ,harga emas mencapai Rp 1.032.578,00 per gram. Kemudian berdasarkan hasil peramalan maka diperoleh persentase kesalahan training data sebesar 1,005 persen serta validasi ramalan dari testing data sebesar 3,93 persen.

Tabel 4

Hasil Peramalan Model ARIMA $(1,1,1)$ untuk 30 Hari Selanjutnya

\begin{tabular}{cccc}
\hline $\begin{array}{c}\text { Urutan } \\
\text { Observasi }\end{array}$ & Nilai Peramalan & Urutan Observasi & Nilai Peramalan \\
\hline 162 & Rp 968.489,00 & 177 & Rp 1.001.237,00 \\
163 & Rp 971.000,00 & 178 & Rp 1.003.432,00 \\
164 & Rp 972.841,00 & 179 & Rp 1.005.653,00 \\
165 & Rp 975.225,00 & 180 & Rp 1.007.863,00 \\
166 & Rp 977.185,00 & 181 & Rp 1.010.091,00 \\
167 & Rp 979.490,00 & 182 & Rp 1.012.312,00 \\
168 & Rp 981.529,00 & 183 & Rp 1.014.548,00 \\
169 & Rp 983.789,00 & 184 & Rp 1.016.781,00 \\
170 & Rp 985.881,00 & 185 & Rp 1.019.025,00 \\
171 & Rp 988.115,00 & 186 & Rp 1.021.270,00 \\
172 & Rp 990.245,00 & 187 & Rp 1.023.523,00 \\
173 & Rp 992.467,00 & 188 & Rp 1.025.778,00 \\
174 & Rp 994.624,00 & 189 & Rp 1.028.040,00 \\
175 & Rp 996.841,00 & 190 & Rp 1.030.306,00 \\
176 & Rp 999.019,00 & 191 & Rp 1.032.578,00 \\
\hline
\end{tabular}

Sumber: Analisis data

Emas merupakan salah satu komoditas utama di dalam perekonomian global. Hal ini dikarenakan minyak dan emas merupakan komoditas paling umum diperdagangkan di dunia dan memimpin variabel ekonomi. Pergerakan harga minyak dan emas berperan penting di dalam perekonomian dunia dan pasar keuangan (Gharib, et.al, 2020). Adanya peningkatan harga emas di masa pandemi Covid-19 disebabkan beberapa faktor. Pelaku pasar merasa khawatir dengan prospek kondisi ekonomi ke depan. Hal ini dikarenakan jumlah kasus positif Covid-19 semakin meningkat sedangkan kondisi ekonomi sedang melemah (cnnindonesia.com). Kemudian, dollar Amerika Serikat yang melemah sehingga menjadi katalis harga emas yang meroket, permintaan terhadap emas, dan adanya volatilitas (liputan6.com, 2020). 
Harga emas yang meroket juga disebabkan hubungan antara Amerika Serikat dan China yang memanas. Kemudian, ditambah adanya program pelonggaran sistem moneter serta stimulus pemerintah yang memberikan likuiditas ke pasar dalam hal pembelian emas (finance.detik.com).

Namun, di sisi lain permintaan terhadap emas pun meningkat. Emas merupakan salah satu investasi yang aman ketika kondisi ekonomi global tidak dalam kondisi yang baik. Emas merupakan safe haven untuk Negara Amerika Serikat, UK, dan Jerman ((Baur \& Lucey, 2010; Baur \& McDermott, 2010). Selain itu, emas juga merupakan safe haven di masa pandemi Covid-19 (Dutta et al., 2020). Safe haven merupakan instrumen investasi yang tidak mudah dipengaruhi oleh gejolak di kondisi pasar keuangan. Kemudian didukung aset safe haven tidak memiliki indikator pengaruh yang banyak dari suatu pasar keuangan. Hal ini dikarenakan kondisi pandemi Covid-19 membuat perekonomian global memanas sehingga membuat pemerintah dan bank sentral menerapkan kebijakan-kebijakan fiskal dan moneter yang membuat dampak terhadap aset, seperti saham (cnnindonesia.com). Oleh karena itu, masyarakat akan berhati-hati dalam melakukan investasi dan memilih investasi yang safe haven.

Penelitian Abdullah (2012) melalui model ARIMA melakukan peramalan harga koin emas batangan. Hasil penelitian menunjukkan harga jual koin emas batangan berada di atas trend dan dianggap sebagai investasi yang layak. Penelitian Guha dan Bandyopadhyay (2016) juga menggunakan model ARIMA untuk melakukan peramalan harga emas India dan menunjukkan hasil bahwa harga emas tersebut mengalami peningkatan. Investasi merupakan salah satu cara masyarakat dalam menanamkan modal dan mendapatkan keuntungan di kemudian hari. Oleh karena itu, saat ini banyak masyarakat yang tertarik melakukan kegiatan tersebut. Dalam berinvestasi pastinya harus mengetahui return dan risiko yang akan dihadapi kelak. Sebelum pandemi Covid19, banyak masyarakat yang tertarik melakukan investasi saham. Hal ini dikarenakan investasi saham memiliki tingkat return yang tinggi meskipun tingkat risiko yang tinggi pula sehingga saat ini masyarakat lebih tertarik melakukan investasi emas. Terdapat 5 jenis investasi emas yaitu sebagai berikut (Mahena et al., 2015) :: yaitu (1) Investasi perhiasan emas. Emas yang dibeli berupa perhiasan; (2) Investasi emas batangan. Dalam memiliki emas batangan dibutuhkan sertifikat yang dikeluarkan oleh PT. Aneka Tambang Unit Logam Mulia; (3) Investasi emas secara trading online. Emas yang dijual atau dibeli dengan cara kontrak pada jumlah emas tertentu dan pada tanggal tertentu; (4) Investasi sertifikat emas. Investasi tersebut berupa sertifikat pembelian emas; (5) Investasi keping emas. Investasi tersebut dalam bentuk kepingan emas dan nilainya ditentukan oleh kandungan emasnya. Saat ini, investasi emas mudah dilakukan. Hal ini dikarenakan emas lebih familiar dikenal oleh masyarakat, khususnya ibu rumah tangga. Salah satunya dapat dibuktikan pada penelitian yang mengenai sikap ibu rumah tangga terhadap emas di Kecamatan Kutoarjo. Pada penelitiannya menghasilkan bahwa 1) Ibu rumah tangga cenderung berpikir bahwa emas dapat dijadikan investasi. Hal ini dikarenakan harga emas cenderung naik. Selain itu, emas sebagai perlindungan beberapa situasi tak terduga, 2) Ibu rumah tangga menyimpan emas ratarata selama lebih dari satu tahun dan 
digunakan sebagai alat perlindungan dan investasi, 3)Hampir semua ibu rumah tangga di Kutoarjo memahami tujuan keputusan untuk membeli dan menjual emas kembali serta risiko keputusan (Satria, 2016).

\section{SIMPULAN}

Kesimpulan yang diperoleh di dalam penelitian ini menunjukkan bahwa prediksi harga emas 30 hari ke depan terus mengalami peningkatan. Nilai persentase kesalahan training data sebesar 1,005 persen serta validasi ramalan dari testing data sebesar 3,93 persen. Pembeda dari penelitian-penelitian sebelumnya, terutama sebelum terjadinya Covid-19, pada penelitian ini menunjukkan bahwa emas benar-benar merupakan safe haven. Hal tersebut ditunjukkan dengan adanya peningkatan harga emas di kondisi perekonomian yang belum baik seperti saat ini. Saran yang dapat ditujukan kepada investor dalam penelitian ini yaitu dalam melakukan investasi emas terutama di masa Pandemi Covid-19 sebaiknya investor perlu memperhatikan pergerakan harga emas dan memperhatikan kondisi perekonomian.

\section{DAFTAR PUSTAKA}

Abdullah, L. (2012). ARIMA model for gold bullion coin selling prices forecasting. International Journal of Advances in Applied Sciences, 1(4), 153-158.

Andriyanto, T. (2017). Sistem Peramalan Harga Emas Antam Menggunakan Double Exponential Smoothing. INTENSIF. https://doi.org/10.29407/intensif.v1i1.531.

Baur, D. G., \& Lucey, B. M. (2010). Is gold a hedge or a safe haven? An analysis of stocks, bonds and gold. Financial Review. https://doi.org/10.1111/j.15406288.2010.00244.x.

Baur, D. G., \& McDermott, T. K. (2010). Is gold a safe haven? International evidence. Journal of Banking and Finance. https://doi.org/10.1016/j.jbankfin.2009.12.008.

biz.kompas.com. (2020). Investasi Emas Jadi Pilihan Terbaik di Masa Pandemi , Ini Alasannya. Diakses dari biz.kompas.com/read/2020/05/28/135638328/investasi-emasjadi-pilihan-terbaik-di-masa-pandemi-ini-alasannya Tanggal 17 Agustus 2020.

Christian, D., \& Halim, S. (2016). Peramalan Multivariate untuk Menentukan Harga Emas Global. Jurnal Teknik Industri. https://doi.org/10.9744/jti.18.2.137-144.

cnbcindonesia.com. (2020). April-Juni Waktu yang Tepat Beli Emas, Ini Penjelasannya. Diakses dari cnbcindonesia.com/market/20200403150731-17-149650/april-juniwaktu-yang-tepat-beli-emas-ini-penjelasannya Tanggal 22 Agustus 2020.

cnbcindonesia.com. (2020). Investor Cari Aman Jadi Penyebab Harga Emas Naik. Diakses dari cnnindonesia.com/ekonomi/20200728102109-92-529639/investor-cari-amanjadi-penyebab-harga-emas-naik Tanggal 24 Agustus 2020.

cnbcindonesia.com. (2020). Alasan Emas Jadi Investasi Aman saat Corona. Diakses dari cnnindonesia.com/ekonomi/20200728124339-92-529711/alasan-emas-jadi-investasiaman-saat-corona Tanggal 24 Agustus 2020.

covid19.go.id/peta-sebaran

Dutta, A., Das, D., Jana, R. K., \& Vo, X. V. (2020). COVID-19 and oil market crash: Revisiting the safe haven property of gold and Bitcoin. Resources Policy. https://doi.org/10.1016/j.resourpol.2020.101816. 
Gharib, C., Mefteh-Wali, S., \& Jabeur, S. B. (2020). The bubble contagion effect of COVID-19 outbreak: Evidence from crude oil and gold markets. Finance Research Letters, 101703. doi:10.1016/j.frl.2020.101703.

Guha, B., \& Bandyopadhyay, G. (2016). Gold price forecasting using ARIMA model. Journal of Advanced Management Science, 4(2).

KURNIA, M. T., NUGRAHANI, E. H., \& SUMARNO, H. (2014). Analisis Wavelet Dan Arima Untuk Peramalan Harga Emas Pt. Antam Tbk Indonesia. Journal of Mathematics and Its Applications, 13(2), 11. https://doi.org/10.29244/jmap.13.2.1122.

Kusumadewi, Felasufah. (2014). Peramalan Harga Emas Menggunakan Feedforward Neural Network dengan Algoritma Backpropagation. Skripsi Universitas Negeri Yogyakarta.

liputan6.com. (2020). 3 Faktor yang Tentukan Pergerakan Harga Emas Pekan Ini. Diakses dari liputan6.com/bisnis/read/4220231/3-faktor-yang-tentukan-pergerakan-hargaemas-pekan-ini Tanggal 24 Agustus 2020.

Mahena, Y., Rusli, M., \& Winarso, E. (2015). Prediksi Harga Emas Dunia Sebagai Pendukung Keputusan Investasi Saham Emas Menggunakan Teknik Data Mining. Kalbiscentia Jurnal Sains Dan Teknologi, 2(1), 36-51. http://files/511/Mahena et al. 2015 - Prediksi Harga Emas Dunia Sebagai Pendukung Keputu.pdf.

Mentacem, N. A., \& Kurniawati, Y. (2016). Penerapan Metode ARIMA untuk Meramalkan Harga Emas Terhadap Mata Uang Dolar Amerika Serikat. 40-46.

money.kompas.com. (2020). Harga Emas Dunia Turun dalam 3 Hari Berturut-turut, Ini Penyebabnya. Diakses dari money.kompas.com/read/2020/05/28/080708226/hargaemas-dunia-turun-dalam-3-hari-berturut-turut-ini-penyebabnya Tanggal 22 Agustus 2020.

Nicola, M., Alsafi, Z., Sohrabi, C., Kerwan, A., Al-Jabir, A., Iosifidis, C., ... \& Agha, R. (2020). The socio-economic implications of the coronavirus and COVID-19 pandemic: a review. International journal of surgery.

properti.kompas.com. (2020). Saat Pandemi, Pilih Investasi Emas atau Properti?. Diakses dari properti.kompas.com/read/2020/08/01/102111821/saat-pandemi-pilih-investasiemas-atau-properti?page=all Tanggal 17 Agustus 2020.

Salisu, A. A., Vo, X. V., \& Lawal, A. (2020). Hedging oil price risk with gold during COVID-19 pandemic. Resources Policy, 101897

Santoso, Denny Achmad. (2013). Pemodelan Arima Untuk Peramalan Harga Emas. Undergraduate thesis, STIKOM Surabaya.

Satria, A. S. (2016). Sikap Ibu Rumah Tangga terhadap Emas di Kecamatan Kutoarjo. Eksis, XI(1), 1-21. 